\title{
R\&D cooperation or competition in the presence of cannibalization
}

\author{
Paul Belleflamme*
}

June 6, 2000

\begin{abstract}
$R \& D$ cooperation is reconsidered in situations where firms direct R\&D activities towards a new product that cannibalizes the firms' existing products. For soft cannibalization, the welfare-maximizing arrangement between firms involves, for low $R \& D$ costs, the formation of a separate entity that independently chooses both the output level of the new good and the level of $R \& D$ expenditures and otherwise, joint decisions about $R \& D$ but independent decisions about production. Yet, as cannibalization increases, firms find it unprofitable to market the new good unless they collaborate more narrowly. Merger should then be permitted for the socially desirable introduction of the new good.
\end{abstract}

JEL classification codes: L13, O32.

Keywords: R\&D cooperation, joint ventures, cannibalization.

*Department of Economics, Queen Mary and Westfield College, Mile End Road, London E1 4NS (phone: + 44207882 5587, fax: +44 208983 3580, e-mail: p.belleflamme@qmw.ac.uk, home page: http://www.qmw.ac.uk/ ugte186/). This research has been initiated when I was at CITA, University of Namur (Belgium). Financial support of the Belgian Federal Office for Scientific, Technical and Cultural Affairs (O.S.T.C. Interuniversity Poles of Attraction, Phase IV, program P4/31) is gratefully acknowledged. I thank Jean Hindriks for useful comments on an earlier draft. Errors are my own. 


\section{Introduction}

Over the last decade, an abundant literature has investigated the issue of cooperative versus non-cooperative Research and Development (R\&D) in oligopolistic industries. This literature starts from the observation that different aspects of $\mathrm{R} \& \mathrm{D}$ generate incentives for firms to behave strategically, and thereby entail a spread between private and social incentives to conduct R\&D. Major recent contributions have examined the question of whether R\&D cooperation can be an effective means to eliminate or reduce such spread. ${ }^{1}$ They have highlighted the primary benefit and disadvantage of $\mathrm{R} \& \mathrm{D}$ cooperation in the presence of positive spillovers. One the one hand, by internalizing spillovers across firms, $R \& D$ cooperation may raise the incentive to conduct $R \& D$ and hence the total amount of $R \& D$. On the other hand, when the firms conducting $R \& D$ are rivals on the product market, they realize that their $R \& D$ investment makes their rivals tougher competitors; in this case, the effect of $R \& D$ cooperation may be to reduce the incentive to conduct $R \& D$. The total effect has been shown to depend on the degree of knowledge spillover between the firms and on the costs of R\&D activities. For instance, it is established that when spillovers are sufficiently large, R\&D cooperation (with subsequent competition at the output stage) leads to more output, R\&D, and welfare than non-cooperation.

This literature considers that firms conduct $R \& D$ because it can generate the knowledge to produce existing products at lower costs or to produce new products. In the latter case, it is generally assumed that the new products are independent of any other products the firms are currently producing. In a number of situations, however, such assumption seems rather restrictive: it is indeed often the case that new products combine the characteristics of existing products and appear thus as substitutes for these existing products. In other words, the introduction of the new product by parent firms might come at the expense of the sales of the parents' existing products, a phenomenon known as cannibalization. The following two stories illustrate this point.

- In May 1999, Eastman Kodak Co. (Kodak) announced the centerpiece of its new "digital strategy", a joint venture with America Online Inc

\footnotetext{
${ }^{1}$ See, e.g., d'Aspremont and Jacquemin (1988), Katz and Ordover (1990), Kamien, Muller and Zang (1992), Suzumura (1992), De Bondt, Slaets, and Cassiman (1992), Bensaïd, Encaoua, and Winckler (1994), Leahy and Neary (1997).
} 
(AOL), called "You've Got Pictures!". The aim of the joint venture is to allow consumers to drop Kodak $35 \mathrm{~mm}$ film off at the drugstore and have a roll of 24 pictures digitally scanned and uploaded into their AOL accounts. From there, consumers will be able to E-mail the images to friends, order reprints or gifts, or download high-resolution copies that can be edited on a PC. Kodak and AOL said they will make joint investments in advertising and marketing, product development, and ongoing support. The two companies will share in revenues from the venture. Though commentators agree that it was critical for Kodak to extend its name to digital since the technology represents a long-term threat to its core franchise in $35 \mathrm{~mm} \mathrm{film}^{2}$, it took quite a long time for Kodak's decision to take shape. As a Kodak's official acknowledged it back in 1997, "Kodak has taken care that its new digital products encroach as little as possible on its film business. (...) There is no doubt about the quality of Kodak's technology but the fear of cannibalization always slowed things down." 3

- In its most basic form, Internet-on- $T V$ displays on television some of the same services (the Web and e-mail) now available to PC users. Yet the long-term future of the Internet-on-TV market lies more in using Internet technologies cost-effectively to support and supplement what TV viewers do today — watch television — not just bring existing PC-oriented Internet content and services to viewers through their television monitor. Analysts of the Internet-on-TV arena underline three major trends. First, by combining standards and technologies from computing, consumer electronics, and telephony, Internet-on-TV is fertile ground for innovative applications. Second, alliance and acquisition will characterize the near future in this market as participants partner to share development costs, overcome marketing weakness, gain access to content and broadband networks, and spread technology and investment risks. Third, Internet-on-TV threatens to draw customers away from today's Internet service providers (ISP), which are among the major players on the market."An ISP can preempt such damage by launching its own Internet-on-TV service, but it must differentiate its

\footnotetext{
${ }^{2}$ Businessweek Online (August 2, 1999), at http : //www . businessweek . com/1999/99/31/ b3640098. htm.

${ }^{3}$ D. Strickland (Kodak's former vice-president for software) in "Can George Fisher Fix Kodak?", Business Week Magazine (October 20, 1997).
} 
new TV-based offering from that of its computer-targeted service or risk slicing into the revenues it now collects from PC-based customers." ${ }^{4}$

When firms conduct R\&D to produce a new product that directly competes with their existing products, the issue of non-cooperative versus cooperative $R \& D$ encompasses three additional features. First, R\&D activities have to be appreciated for their effects on the competition not only on the 'new' market, but also on the 'old' markets. Next, in a similar vein, the firms' individual rationality for engaging in R\&D and production of the new product has to be carefully checked: profits on the new product market must cover not only R\&D expenditures but also profits lost on the 'old' markets. Finally, since the firms can be active on different markets, a wider range of cooperation modes opens for them; that is, firms can choose to take independently or jointly their decisions regarding $\mathrm{R} \& \mathrm{D}$ and/or production of the new good and/or production of the existing goods.

The aim of the present paper is to address these three additional features within an analytical model. In order to keep the model tractable, the analysis is limited to a symmetric two-firm setting with full knowledge spillovers, and with linear demands and marginal costs. Despite its simplicity, several important points emerge.

1. The presence of cannibalization does not challenge the d'Aspremont and Jacquemin (1988) result according to which cooperation on R\&D is welfare-improving when spillovers are sufficiently large. We indeed show that none of the arrangements involving uncoordinated R\&D activities will ever be chosen either by the firms or by a regulator willing to maximize social welfare.

2. When cannibalization is not too strong, social welfare is maximized, for high $\mathrm{R} \& \mathrm{D}$ costs, when firms form a $R \dot{E} D$ Cartel ( $R D C$ ) and, for low $\mathrm{R} \& \mathrm{D}$ costs, when they form an Independent Joint Venture (IJV). In the RDC option, firms coordinate their $\mathrm{R} \& \mathrm{D}$ decisions in the first stage to maximize combined industry profits but still act independently in the second (production) stage; in the IJV option, a new firm is set up which independently chooses the second-stage output level of the

\footnotetext{
${ }^{4}$ See "Internet on Television", Media Futures Program, SRI Consulting (June 1998) at http://future.sri.com:8080/dv3adm/iTV.
} 
new good, and which chooses the first-stage expenditures of R\&D that maximize its own profit.

3. When cannibalization is strong, firms might find it unprofitable to market the new good unless they are allowed to narrowly collaborate with each other; at the limit, a complete merger will be the only option under which the new good will appear.

The rest of the paper is organized as follows. Section 2 describes the various collaborative agreements that the firms may adopt, as well as the main assumptions of the modeling framework. Section 3 solves the two-stage games corresponding to the various options. Section 4 compare the solutions in terms of firms' profits, consumers surplus and social welfare. Section 5 concludes.

\section{The models}

We consider an industry where two firms act initially as local monopolists on their respective market (firms 1 and 2 respectively produce goods $X$ and $Y$ which are perfectly differentiated). Let us suppose that, at some point in time, both firms have the opportunity to start marketing a new good (noted $Z$ ) that is substitutable to the existing goods $X$ and $Y$. There exists for good $Z$ some process innovation that requires two complementary and specific assets. Suppose also that these assets are costly to develop and that none of the firms owns both of the assets simultaneously. In order to obtain the benefits of the process innovation, firms therefore have to collaborate in some way or another. Different options are open to them according to whether they choose to coordinate their $\mathrm{R} \& \mathrm{D}$ decisions (i.e., the amounts of specific assets they invest) and/or their production decisions (i.e., the quantities of the new good and of the existing goods they put on the market). More specifically, we consider the following six options. In each option, a two-stage game takes place where $\mathrm{R} \& \mathrm{D}$ decisions precede production decisions.

1. The first option is to form a Technology Sharing Cartel (TSC) in which firms agree ex ante to share technological knowledge resulting from $\mathrm{R} \& \mathrm{D}$ activities. Aside from that, there is no other form of cooperation between firms: each firm independently chooses its R\&D investment and its output level for the new good, as well as for its existing ('old') good. 
2. The second option goes a step further by introducing cooperation in the joint development of $R \mathscr{E} D$ projects. That is, firms coordinate their $\mathrm{R} \& \mathrm{D}$ decisions in the first stage to maximize combined industry profits but still act independently in the second (production) stage. To conform to the literature, we say in this case that firms create a RED Cartel (RDC).

3. The third option also goes a step further with respect to the first option, but by introducing cooperation in the production of the new good rather than in R\&D decisions. Firms create here a Production Joint Venture (PJV) which chooses the second-stage output level of the new good, independently of the parent firms. As for the parent firms, they noncooperatively choose the output levels of their old good at the second stage, and their R\&D investment at the first stage of the game.

4. In the fourth and fifth options, a new firm is set up which, as the PJV, independently chooses the second-stage output level of the new good. Furthermore, these two options also involve some form of cooperation in $\mathrm{R} \& \mathrm{D}$ decisions:

(a) in the Cooperative Joint Venture (CJV) option, the parent firms coordinate their R\&D investments in order to maximize combined industry profits (as in the RDC option) $;^{5}$

(b) on the other hand, in the Independent Joint Venture (IJV) option, it is the new firm that bears the cost of the specific assets and chooses the level of assets that maximizes its own profit.

\footnotetext{
${ }^{5}$ We coined the term "Cooperative Joint venture" to indicate that a joint venture is set up as a separate entity, and that there exists some cooperation between the parent companies as far as R\&D is concerned. It must be noted, however, that the EC competition law gives to this term a specific meaning, which differs from the one we use here. Under the EC Merger Regulation, 'cooperative' joint ventures are distinguished from 'concentrative' joint ventures. The latter are defined by two criteria: first, the joint venture must perform on a lasting basis all the functions of an autonomous entity; second, there must be no coordination of competitive behavior of the partiesamongst themselves or between them and the joint venture (Article $3(2)$ ). Any joint venture which does not satisfy these two requirements is considered as cooperative. Note that because the distinction between the two types of joint ventures has proven to be one of the most difficult issues in the implementation of the Merger Regulation, a 1998 Notice on "the concept of Full-Function Joint Ventures" has replaced the 1994 Notice on the distinction between concentrative and cooperative joint ventures.
} 


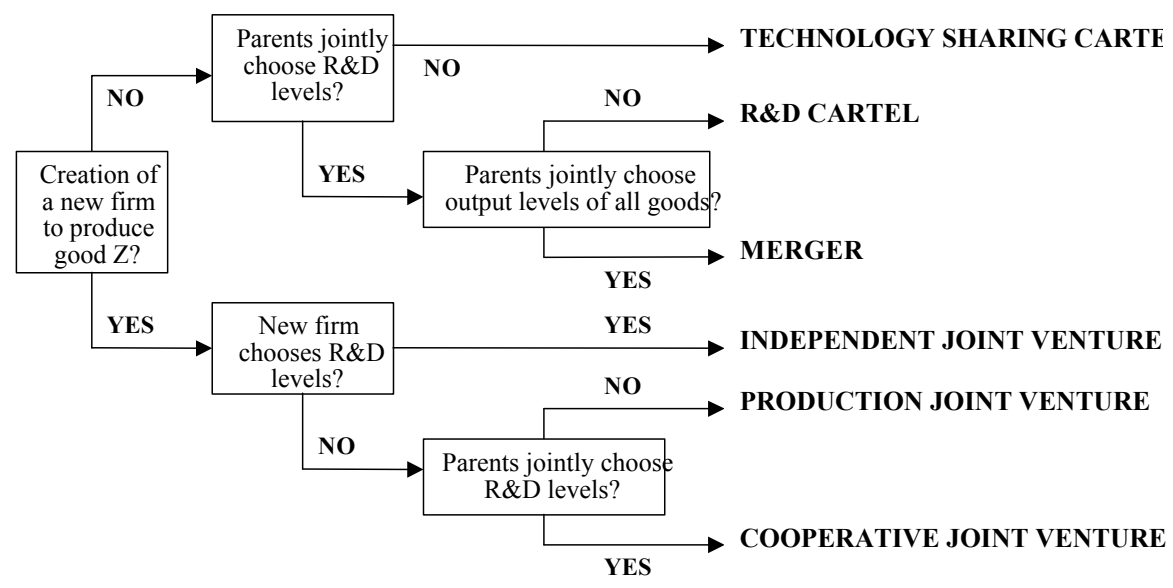

Figure 1: Alternative arrangements

5. Finally, total cooperation is reached in the Merger (MER) option, where firms decide to form a single entity which chooses R\&D investments in the first stage and output levels of all goods in the second stage to maximize total industry profits.

To sum up, the six options are as follows (see Figure 1 for a schematic representation). Either parent firms decide to produce separately the new good and three options are open: (i) no cooperation (Technology Sharing Cartel), (ii) cooperation in R\&D ( $R \mathcal{E} \mathcal{D}$ Cartel), or (iii) cooperation in both $\mathrm{R} \& \mathrm{D}$ and production of all three goods (Merger). Or parent firms delegate the production of the new good to a new entity (a Joint Venture) and, again, three options are open regarding $\mathrm{R} \& \mathrm{D}$ decisions: either $\mathrm{R} \& \mathrm{D}$ decisions are also delegated to the new entity (Independent Joint Venture), or they are left to parent firms which can then act non-cooperatively (Production Joint Venture) or cooperately (Cooperative Joint Venture).

Our goal is to compare the respective performance of the six options with respect to output, $R \& D$, industry profits, consumers surplus and social welfare. As will become clear below, such comprehensive comparison seems hardly tractable without selecting some specific model. The six options indeed involve a series of effects that affect differently firms and consumers and that cannot be balanced a priori. More precisely, complementary R\&D activities and substitutability of the products create three types of externalities. 
- First, because of knowledge spillovers, there is a free-riding effect when R\&D levels are chosen independently by the two firms; each firm tries to free-ride on the efforts of its rival by lowering the level of its own specific and costly assets. Underprovision of $R \& D$ is likely to have a negative effect on consumers surplus and an ambiguous effect on industry profits.

- Second, production of the new good within a single firm entails two contrasting effects. On the one hand, it removes competition on this market, which tends to increase firms profits but to reduce consumers surplus (cartelization effect). On the other hand, independent production of the new good entails a cannibalization effect on the sales of the existing goods; this effect is detrimental to firms profits but beneficial to consumers surplus.

Table 1 highlights which of the three effects occur in each of the six options.

\begin{tabular}{c|ccc} 
& Free riding & Cartelization & Cannibalization \\
\hline \hline TSC & Yes & No & No \\
RDC & No & No & No \\
MER & No & Yes & No \\
PJV & Yes & Yes & Yes \\
CJV & No & Yes & Yes \\
IJV & No & Yes & Yes
\end{tabular}

Table 1: Presence of externalities in the various options

The balance between these various effects will depend on three key parameters: the degree of knowledge spillovers, the cost of $\mathrm{R} \& \mathrm{D}$, and the degree of cannibalization between new and old goods. In what follows, we somehow simplify the analysis by assuming that the spillovers of the R\&D benefits between the firms reach their maximum level. This simplification allows us to focus on the interplay between the costs of $R \& D$ activities and the intensity of cannibalization. Specifically, we make the following set of assumptions.

(A1) Let goods $X, Y$ and $Z$ be produced in respective quantities $x, y$ and $z$, and sold at respective prices $p, q$ and $r$. Demands for the three goods 
are derived from the following quadratic utility of a representative consumer:

$$
U(x, y, z)=\alpha(x+y+z)-\frac{1}{2}\left(x^{2}+y^{2}+z^{2}\right)-\gamma(x+y) z,
$$

where $\gamma \in[0,1]$ measures the degree of substitutability between the new good $Z$ and the old goods $X$ and $Y$ (for $\gamma=0, Z$ is independent of $X$ and $Y$; for $\gamma=1$, it is a perfect substitute). ${ }^{6}$ Maximizing utility subject to the budget constraint yields the following linear inverse demand schedule in the region of quantities where prices are positive:

$$
\left\{\begin{array}{l}
p=\alpha-x-\gamma z \\
q=\alpha-y-\gamma z \\
r=\alpha-z-\gamma(x+y) .
\end{array}\right.
$$

Note that $z$ represents total quantity of the new good; in particular, when firms 1 and 2 produce separately good $Z$ (i.e., in options TSC and RDC), we have $z \equiv z_{1}+z_{2}$.

(A2) Let $a_{1}$ and $a_{2}$ denote the amount of the two assets respectively chosen by firms 1 and 2 . We define the marginal cost of production of the new product as $c_{z}=c-a_{1}-a_{2}$ (with $0<c<\alpha$ ); this formulation emphasizes that spillovers are complete (since marginal cost of production is reduced by the sum of both $R \& D$ efforts).

(A3) Let $c$ also measure the marginal cost of production of the two existing goods (meaning that, before any process innovation, all three goods have the same marginal cost of production). ${ }^{7}$

(A4) Monetary expenses incurred to obtain a level of specific assets $a_{i}$ are given by $(s / 2) a_{i}^{2}$; such quadratic costs reflect the existence of diminishing returns to R\&D expenditures; parameter $s$ measures the cost of development of the firms' specific assets.

We are now in a position to solve the two-stage games corresponding to each of the six options and to compare their welfare effects.

\footnotetext{
${ }^{6}$ Parent firms are thus in a symmetric position in terms of cannibalization. Section 5 discusses the effects of relaxing this assumption.

${ }^{7}$ This assumption is made for technical convenience. Assuming different marginal costs of production would significantly complicate the analysis without any real gain in insight (we would just have to express additional conditions to ensure that second-order conditions are satisfied and that equilibrium solutions are interior).
} 


\section{Resolution of models}

As a preliminary step, we need to compute the profit levels that firms 1 and 2 can achieve when the new good is not produced (and no R\&D is performed). Firms 1 and 2 act thus as local monopolists. With $z=a_{1}=a_{2}=0$, one easily exploit the symmetry of the model to derive the following equilibrium quantities and profits:

$$
\begin{aligned}
x_{0} & =y_{0}=(\alpha-c) / 2, \\
\Pi_{0}^{1} & =\Pi_{0}^{2}=\frac{1}{4}(\alpha-c)^{2} \equiv \Pi_{0} .
\end{aligned}
$$

Expression (3) can be interpreted as the reservation profit level each firm must obtain for accepting to enter into some form of cooperative agreement for the production of good $Z$; in other words,

$$
\Pi^{i} \geq \Pi_{0} \quad(i=1,2)
$$

expresses the participation constraint for firm $i$ in each of the six options.

We can also easily compute the consumer surplus and social welfare in that situation:

$$
\begin{aligned}
S_{0} & =\frac{1}{2}\left(x_{0}^{2}+y_{0}^{2}\right)=\frac{1}{4}(\alpha-c)^{2}, \\
W_{0} & =S_{0}+\Pi_{0}^{1}+\Pi_{0}^{2}=\frac{3}{4}(\alpha-c)^{2} .
\end{aligned}
$$

In a similar vein, expression (5) can be interpreted as a 'reservation social welfare level' under which the introduction of the new good would be detrimental to society.

We can now turn to the resolution of the six two-stage games. We first describe the different maximization programs for the two stages in each of the six options; to facilitate the exposition, we distinguish the options according to whether the new good is produced by separate entities or by a single entity; the Merger option is treated separately. All equilibrium asset and output levels are presented in a synthetic table in Appendix A.

\subsection{Separate production of the new good (TSC, RDC)}

When firms 1 and 2 form either a Technology Sharing Cartel (option TSC) or a $R \& D$ Cartel (option RDC), they produce each a quantity $z_{i}$ of good $Z$. The second (production) stage is the same in the two games. Firm 1 faces 
the following maximization programs (where superscript $K$ is equal to either $T$ or $R$ to denote, respectively, options TDC and RDC, and where $\beta \equiv \alpha-c$ is a measure of the size of the three markets):

$$
\begin{aligned}
\max _{x, z_{1}} \Pi_{1}^{K}\left[x, y, z_{1}, z_{2}, a_{1}, a_{2}\right]= & (p-c) x+\left[r-\left(c-a_{1}-a_{2}\right)\right] z_{1} \\
= & {\left[\beta-x-\gamma\left(z_{1}+z_{2}\right)\right] x+} \\
& {\left[\beta+a_{1}+a_{2}-z_{1}-z_{2}-\gamma(x+y)\right] z_{1} . }
\end{aligned}
$$

Firm 2 faces a similar program. Solving for the system of four first-order conditions, one derives the output equilibria for any given levels of the assets $a_{1}$ and $a_{2}$. Using these output equilibria, we can write the second stage equilibrium gross profit of firm $i(i=1,2)$ as

$$
\Pi_{i}^{K}\left[a_{1}, a_{2}\right]=\Pi_{i}^{K}\left[x^{K}\left(a_{1}, a_{2}\right), y^{K}\left(a_{1}, a_{2}\right), z_{1}^{K}\left(a_{1}, a_{2}\right), z_{2}^{K}\left(a_{1}, a_{2}\right), a_{1}, a_{2}\right] .
$$

The two options differ with respect to the first (R\&D) stage.

- In option TSC, collaboration is restricted to the (complete) spillover of knowledge; R\&D decisions remain independent. Assets levels at the subgame perfect equilibrium of the two-stage game corresponding to the Technology Sharing Cartel, $a_{i}^{T}$, are determined by simultaneously solving

$$
\max _{a_{i}} \Pi_{i}^{T}\left[a_{1}, a_{2}\right]-(s / 2) a_{i}^{2}, \forall i=1,2 .
$$

- On the other hand, in option $R D C$, firms coordinate their R\&D decisions so as to maximize the sum of their combined profits. That is, equilibrium assets levels corresponding to the R\&D Cartel, $a_{i}^{R}$, are determined by solving

$$
\max _{a_{1}, a_{2}} \Pi_{1}^{R}\left[a_{1}, a_{2}\right]+\Pi_{2}^{R}\left[a_{1}, a_{2}\right]-(s / 2)\left(a_{1}^{2}+a_{2}^{2}\right) .
$$

\subsection{Joint production of the new good (PJV, CJV, IJV)}

Here, the parent firms form a new joint venture (labelled 3) which is responsible for the production of good $Z$. The three options share thus the same second stage where each of the three firms chooses the profit maximizing level of the good it produces. That is, firms 1 to 3 respectively face the 
following maximization programs (where superscript $L$ is either equal to $P$, $I$, or $C$ depending on the joint venture being of the production, independent or cooperative type):

$$
\begin{aligned}
\max _{x} \Pi_{1}^{L}\left[x, y, z, a_{1}, a_{2}\right] & =(p-c) x=(\beta-x-\gamma z) x \\
\max _{y} \Pi_{2}^{L}\left[x, y, z, a_{1}, a_{2}\right] & =(q-c) y=(\beta-y-\gamma z) y \\
\max _{z} \Pi_{3}^{L}\left[x, y, z, a_{1}, a_{2}\right] & =\left[r-\left(c-a_{1}-a_{2}\right)\right] z \\
& =\left[\beta+a_{1}+a_{2}-z-\gamma(x+y)\right] z .
\end{aligned}
$$

Solving for the system of three first-order conditions, one derives the output equilibria for any given levels of the assets $a_{1}$ and $a_{2}$. As above, using these output equilibria, we can write the second stage equilibrium gross profit of firm $j(j=1,2,3)$ as

$$
\Pi_{j}^{L}\left[a_{1}, a_{2}\right]=\Pi_{j}^{L}\left[x^{L}\left(a_{1}, a_{2}\right), y^{L}\left(a_{1}, a_{2}\right), z^{L}\left(a_{1}, a_{2}\right), a_{1}, a_{2}\right] .
$$

Differences appear between the three options regarding first stage $R \& D$ decisions.

- In option PJV, the parent firms independently choose their R\&D investment to maximize their own profits, i.e., the profits they realize on the production of their old good $(X$ or $Y$ ), augmented by half of firm 3's profits. ${ }^{8}$ Assets levels at the subgame perfect equilibrium of the two-stage game corresponding to the Production Joint Venture, $a_{i}^{P}$, are thus determined by simultaneously solving

$$
\max _{a_{i}} \Pi_{i}^{P}\left[a_{1}, a_{2}\right]+(1 / 2) \Pi_{3}^{P}\left[a_{1}, a_{2}\right]-(s / 2) a_{i}^{2} \forall i=1,2 .
$$

- In option $C J V$, firms coordinate their $\mathrm{R} \& \mathrm{D}$ decisions so as to maximize the sum of their combined profits (i.e., total industry profits). That is, equilibrium assets levels corresponding to the Cooperative Joint Venture, $a_{i}^{C}$, are determined by solving

$$
\max _{a_{1}, a_{2}} \Pi_{1}^{C}\left[a_{1}, a_{2}\right]+\Pi_{2}^{C}\left[a_{1}, a_{2}\right]+\Pi_{3}^{C}\left[a_{1}, a_{2}\right]-(s / 2)\left(a_{1}^{2}+a_{2}^{2}\right) .
$$

\footnotetext{
${ }^{8}$ At this stage, we need to make a specific assumption about the division of the joint venture's profits between the two parents. Because parent firms are symmetric, equal splitting appears as a reasonable assumption.
} 
- In option $I J V$, firm 3 is fully independent insofar as it is not only responsible for the production of good $\mathrm{Z}$ but also for the choice of specific assets (and it bears therefore the cost of these assets). As a result, firm 3 is the only active firm at the first stage of the game and determines equilibrium assets levels corresponding to the Independent Joint Venture, $a_{i}^{I}$, by solving

$$
\max _{a_{1}, a_{2}} \Pi_{3}^{I}\left[a_{1}, a_{2}\right]-(s / 2)\left(a_{1}^{2}+a_{2}^{2}\right) .
$$

\subsection{Joint production of all goods (MER)}

In the Merger option, the parent firms merge to form a single entity (noted $m$ ). At the second stage of the game, this firm chooses the profit maximizing levels of output for the three goods; that is, it solves

$$
\begin{aligned}
\max _{x, y, z} \Pi_{m}^{M}\left[x, y, z, a_{1}, a_{2}\right]= & (\beta-x-\gamma z) x+(\beta-y-\gamma z) y \\
& +\left[\beta+a_{1}+a_{2}-z-\gamma(x+y)\right] z .
\end{aligned}
$$

Solving for the system of three first-order conditions, one derives the output equilibria for any given levels of the assets $a_{1}$ and $a_{2}$; using these output equilibria, we can write the second stage equilibrium gross profit of firm $m$ as

$$
\Pi_{m}^{M}\left[a_{1}, a_{2}\right]=\Pi_{m}^{M}\left[x^{M}\left(a_{1}, a_{2}\right), y^{M}\left(a_{1}, a_{2}\right), z^{M}\left(a_{1}, a_{2}\right), a_{1}, a_{2}\right] .
$$

At the first stage, the merged firm chooses the profit maximizing levels of the specific assets, $a_{i}^{M}$, by solving

$$
\max _{a_{1}, a_{2}} \Pi_{m}^{M}\left[a_{1}, a_{2}\right]-(s / 2)\left(a_{1}^{2}+a_{2}^{2}\right) .
$$

\subsection{Synthesis of results}

We need to impose some conditions on the parameters to ensure that the second order conditions are satisfied and that all the endogenous variables (assets, costs, quantities) are positive at equilibrium in every option. Tedious but straightforward computations yield the following set of conditions:

(C1) $\gamma<.477$

(C2) $s>\underline{\mathrm{s}}(\gamma) \equiv \max \left\{\frac{4[(1-\gamma) \alpha+\gamma c]}{\left(2-\gamma^{2}\right)^{2} c} ; \frac{1}{1-\gamma}\right\}$. 
In words, the degree of differentiation between the new good and the old goods must be high enough (i.e., cannibalization cannot be too strong), and investment in R\&D must be costly enough. More specifically, condition (C1) makes sure that $\mathrm{R} \& \mathrm{D}$ levels are nonnegative when they are the lowest, i.e., in option TSC. The first part of condition (C2) guarantees that marginal cost for the new good is nonnegative when R\&D levels are the highest, i.e., in option IJV; the second part of condition (C2) ensures that nonnegative quantities of old goods are produced in the worst-case scenario for them, i.e., in the merger option.

We present in Appendix 6.1 the perfect equilibrium levels of industry assets and of output for the three goods in the six options. We also indicate how these results can be used to derive firms' profits, consumers surplus and social welfare.

\section{Welfare analysis}

As mentioned above, because the new product is a substitute for the old ones (i.e., for $\gamma>0$ ), the sales it generates come at their expense (cannibalization effect). In such a context, R\&D activities not only affect the production of good $Z$ but also the production of good $X$ and $Y$ : other things equal, the higher are the industry $\mathrm{R} \& \mathrm{D}$ efforts and the degree of product substitutability, the higher will be the value of the sale lost on old goods. This introduces two major changes with respect to what has been studied so far in the literature (i.e., the case where $\gamma=0$ ): first, while incentives for $R \& D$ are equivalent in options CJV, IJV and MER for $\gamma=0$, they clearly differ for $\gamma>0$; second, one must now check whether the firms' participation constraint is met (i.e., whether the revenue generated by the new good outweighs the revenue lost on the old good plus the cost of R\&D expenditures).

More practically, the introduction of cannibalization also makes the analysis much more cumbersome: there are six (instead of four) options to compare, for all admissible combinations of two (instead of one) key parametersthe cost of R\&D $(s)$ and the degree of product substitutability $(\gamma)$. In consequence, we will not try to exhaustively rank the six options in terms of industry profits, consumers surplus, and social welfare; even though this task is technically feasible, it will become clear below that some comparisons are of a very limited interest. We focus instead on the most significant results and address the following questions: Given RED costs and the degree of 
product substitutability, which option yields the highest welfare level? Do the interests of firms and consumers diverge or converge for such option? Does the market provide the firms with the correct incentives to engage in such option? We proceed step by step, by comparing first the options sharing some common features. Note that we take the point of view of a second-best regulator who can permit or refuse cooperative arrangements between firms but who cannot interfere with their production and R\&D decisions.

\subsection{Cooperative vs. non-cooperative R\&D}

A first set of results concerns the two options where there is no cooperation in $R \& D$ activities. Simple computations (based on the results presented in Appendix A) show that over the whole admissible range of parameters, the Technology Sharing Cartel is dominated by the RED Cartel, both in terms of industry profits and of consumers surplus. This means that the result of d'Aspremont and Jacquemin (1988) carries over in the presence of cannibalization. It is worth noting, however, that the positive differences in firms' profits, in consumers surplus, and in total welfare between options RDC and TSC decrease with the degree of product substitutability; at the limit, for $\gamma=0.477$ (where R\&D efforts approach zero in option TSC), the differences vanish.

In a similar way, it can be shown that the Production Joint Venture is dominated by the Cooperative Joint Venture both in terms of industry profits and of consumers surplus. Note that, as in the previous finding, the difference between the two options decreases (but does not vanish at the limit) as $\gamma$ increases (i.e., as the cannibalization effect becomes stronger).

Collecting the previous results, we can state the following proposition. ${ }^{9}$

Proposition 1 None of the options involving uncoordinated RED activites (i.e., options TSC and PJV) would ever be chosen either by the firms or by a second-best regulator.

\footnotetext{
${ }^{9}$ The proofs of the following propositions require tedious but straightforward computations based on the results of Table 2; they are omitted here but can be found in a technical appendix available from the author.
} 


\subsection{Socially desirable way to coordinate production}

Besides option PJV which is Pareto-dominated, three other options involve some form of cooperation in production decisions: options CJV, IJV, and MER. As noted above, these options, which provide the same incentives for R\&D when $\gamma=0$, must be clearly distinguished when $\gamma>0$. Because options CJV and IJV share the same production stage (they both involve the set up of a joint venture), their comparison leads to clear cut results. In particular, it can be shown that the Independent Joint Venture is socially more desirable than the Cooperative Joint Venture, but there exists a divergence between consumers surplus (higher in the Independent JV) and industry profits (higher in the Cooperative JV). Intuitively, the divergence comes from the type of $R \& D$ cooperation that takes place in the two options: in the Cooperative JV, assets are chosen so as to maximize industry profits, which are therefore higher; on the other hand, the Independent JV chooses assets so as to maximize profits over the production of good $Z$, which leads to a higher consumers surplus.

Next, it turns out that a similar result holds for the comparison between options IJV and MER: despite the fact that the Merger option leads to higher industry profits, the Independent Joint Venture is socially more desirable than the Merger because of a higher consumers surplus.

Finally, the comparison between options CJV and MER is ambiguous; we have that $\Pi^{M}>\Pi^{C}$ for all $s$ and $\gamma$, but the ranking in terms of consumers surplus and of social welfare depends on the specific values of $\gamma$ and $s$ : roughly speaking, one can say that the Cooperative Joint Venture yields higher consumers surplus and social welfare than a complete merger unless R\&D costs are very low. ${ }^{10}$

The main finding that can be drawn from the previous results is thus the following: when production decisions are coordinated in one way or another, it is socially desirable to let RED efforts be chosen by the independent joint venture, so as to maximize its own profit. In other words, when the production of the new good is conducted by a single firm, it is welfare-enhancing to link coordinated R\&D efforts solely to the production of the new good,

\footnotetext{
${ }^{10}$ For instance, for $\gamma=0.1$ (and provided that $\underline{\mathrm{s}}(\gamma)=(1-\gamma)^{-1}$ ), we have the following ranking: (i) for $\underline{\mathrm{s}}(0.1)=1.111 \leq s<1.209, S_{C}<S_{M}$ and $W_{C}<W_{M}$; for $1.209 \leq s<$ $1.226, S_{C}>S_{M}$ and $W_{C}<W_{M}$; for $s \geq 1.226, S_{C}>S_{M}$ and $W_{C}>W_{M}$. The various threshold values are increasing in $\gamma$ (e.g., for $\gamma=0.4$, the corresponding threshold values are respectively $1.667,1.720$, and 1.757).
} 
leaving thus aside all consideration about cannibalization prospects. This result is summarized in the following proposition.

Proposition 2 Among the four options involving cooperation in production decisions (i.e., options PJV, CJV, IJV, and MER), the Independent Joint Venture leads to the highest consumers surplus and social welfare.

\subsection{Firms' incentives}

A first intuitive result about firms' incentives is that industry profits are higher in the Merger option than in any other option. This is not a surprise insofar as when the firms completely merge, they internalize all externalities and reach thus the highest possible profits. From the above results, we also know that the second on the list is either option CJV or option RDC; simple computations reveal that the Cooperative Joint Venture yields the second highest industry profits provided that the degree of product substitutability and R\&D costs are not too high; otherwise, the R\&D Cartel does. ${ }^{11}$ However, it can also be shown that for those values of $\gamma$ and $s$ where $\Pi^{R}>\Pi^{C}$, it is also true that $\Pi^{R}<\Pi_{0}$, meaning that the participation constraint is not met.

As far as the participation constraint is concerned, it is easy to show that in all options but the Merger option, one can find, for sufficiently high values of $\gamma$, values of $s$ for which the participation constraint is violated (see Appendix 6.2 for a formal statement). Intuitively, as the degree of cannibalization and research costs increase, introduction of the new product becomes less profitable.

The next proposition collects the previous results and review the situation about firms' incentives.

Proposition 3 By completely merging, the firms achieve the highest profits among the six options and always improve upon initial profits (i.e., absent the new good). If complete merger is not allowed, firms will prefer to form a Cooperative Joint Venture, but they might end up with lower profits than in the initial situation if the degree of product substitutability and RED costs are beyond some threshold.

\footnotetext{
${ }^{11}$ More precisely, $\Pi^{C}>\Pi^{R}$ unless $\gamma>0.404$ and $s>\tilde{s}(\gamma)$, with $\tilde{s}^{\prime}(\gamma)<0$ (and with, e.g., $\tilde{s}(0.405)=122.634, \tilde{s}(0.425)=7.955, \tilde{s}(0.45)=3.850$, and $\tilde{s}(0.475)=2.578)$.
} 


\subsection{R\&D Cartel or Independent Joint Venture, or ...?}

Collecting the results from Propositions 1 and 2, we have already established the following rankings in terms of consumer surplus and social welfare: the R\&D Cartel dominates the Technology Sharing Cartel, and the Independent Joint Venture dominates the Cooperative and the Production Joint Ventures, as well as the Merger. In other words, the highest social welfare and consumers surplus levels will be reached under either option RDC or option $I J V$. The remaining issues are thus the following. First, we must identify the regions in the $(\gamma, s)$ space where one option should be preferred over the other, and where firms' and consumers' interest converge or diverge. Next question which arises naturally is whether the socially desirable option is likely to be chosen by the firms in the absence of public intervention. We already know from Proposition 3 that the answer is no since options RDC and IJV are both dominated in terms of profits by options MER and CJV. We could then consider that antitrust authorities, acting as a second-best regulator, would prohibit the formation of any merger or cooperative joint venture. Yet, we also know that options RDC and IJV might violate the participation constraint. We need thus to investigate what the authorities should decide in such case (assuming that they cannot force firms to engage in unprofitable agreements).

\subsubsection{RDC vs. IJV}

The answer to the first question is depicted in Figure 2 where the R\&D Cartel and the Independent Joint Venture are compared with respect to industry profits, consumers surplus, and social welfare. It turns out that the admissible range of the $(\gamma, s)$ space has to be divided into four areas where the following rankings obtain: ${ }^{12}$

- area 1 is characterized by $\Pi^{I}>\Pi^{R}, S^{I}<S^{R}$, and $W^{I}<W^{R}$;

- area 2 is characterized by $\Pi^{I}>\Pi^{R}, S^{I}<S^{R}$, and $W^{I}>W^{R}$;

- area 3 is characterized by $\Pi^{I}>\Pi^{R}, S^{I}>S^{R}$, and $W^{I}>W^{R}$;

- area 4 is characterized by $\Pi^{I}<\Pi^{R}, S^{I}>S^{R}$, and $W^{I}>W^{R}$.

\footnotetext{
${ }^{12}$ Only part of condition (C2) is represented in Figure 2, i.e., $s>(1-\gamma)^{-1}$. The second part is also satisfied provided that $(\alpha / c) \leq\left(4+\gamma^{4}-4 \gamma\right) /\left[4(1-\gamma)^{2}\right]$.
} 


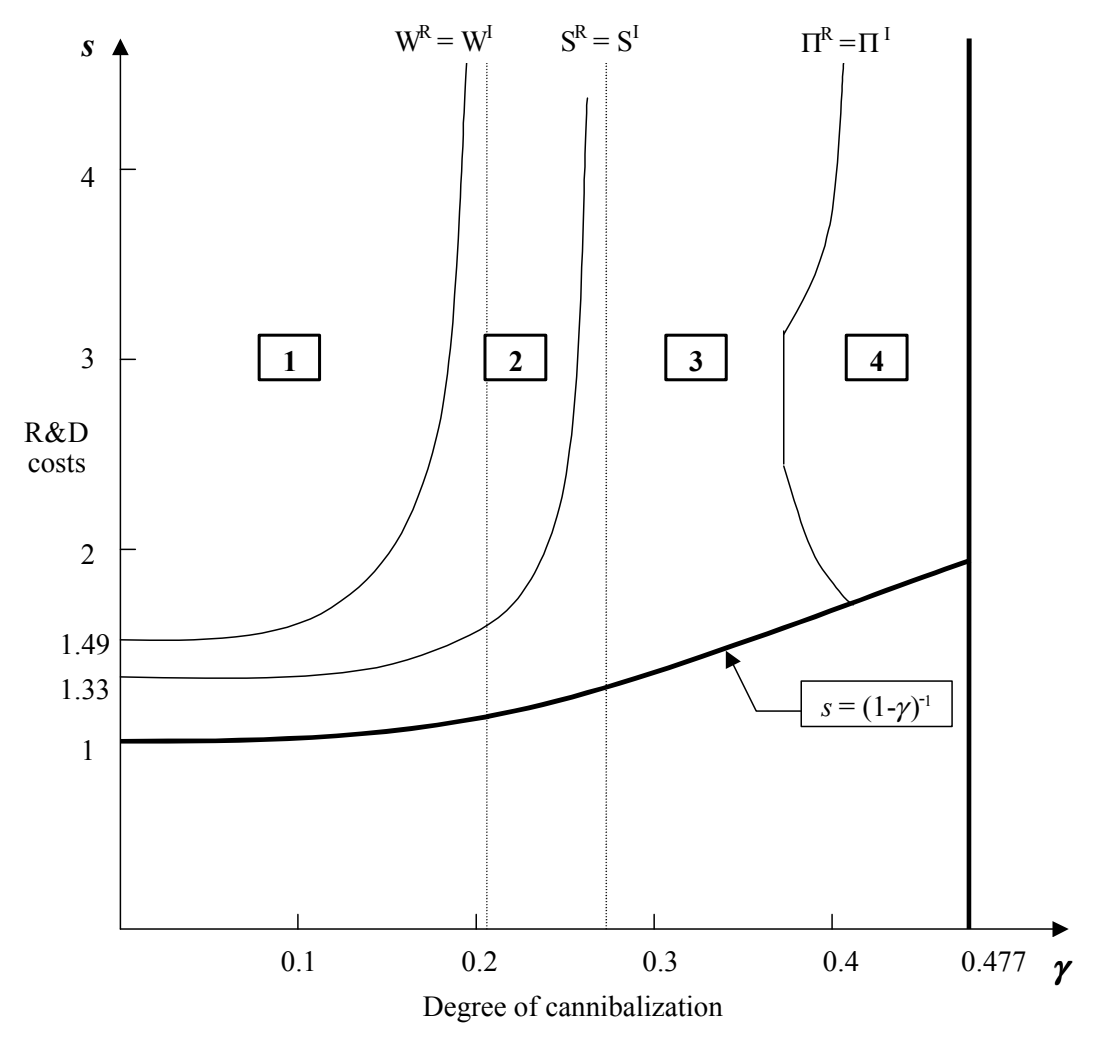

Figure 2: Comparison between options RDC and IJV

In terms of social welfare, option RDC should be chosen only in area 1 (i.e., for values of $\gamma$ no larger than 0.206 and for values of $s$ sufficiently large); in the other three areas, social welfare is maximized under option IJV. ${ }^{13}$ Regarding the comparison between firms' and consumers' interests, area 3 is the only region of parameters where firms and consumers agree (they all prefer option IJV); in the other three areas, interests diverge: in areas 1 and 2, firms prefer option IJV while consumers prefer option RDC; the opposite prevails in area 4.

To understand the intuition behind these results, it is worth recalling that options RDC and IJV differ both at the production and at the R\&D stages, which induces a complex interplay of countervailing forces. At the production stage, option RDC involves separate production of good $Z$ by firms 1 and 2

\footnotetext{
${ }^{13}$ It is important to note that in a large part of these three areas, option RDC is dominated not only by option IJV but also by option CJV.
} 
while, in option IJV, it is a new independent firm that is the single producer of good $Z$. As indicated above, this difference entails contrasting effects: on the one hand, firms internalize the cannibalization effect in option RDC but not in option IJV; on the other hand, option RDC induces competition on the new good market whereas option IJV does not. An increase in the degree of product substitutability reinforces the former effect (internalizing the cannibalization effect becomes more profitable) but does not affect the latter; therefore, for given R\&D investements, the balance between the two effects is more favorable (in terms of social welfare) to option RDC as $\gamma$ increases.

At the R\&D stage, levels of specific assets are chosen so as to maximize industry profits in option RDC, and the joint venture's profits only in option IJV; the implications of this difference are best viewed by examining the firstorder conditions with respect to the level of specific assets $a_{i}$ (where account is taken of the first-order conditions at the production stage, and of the fact that, due to symmetry of the model, $x^{K}=y^{K}(K=R, I)$ and $\left.z_{i}^{R}=z_{j}^{R}\right)$ :

$$
\begin{aligned}
\text { (IJV) } s a_{i}^{I} & =\underbrace{z^{I}}_{\mathrm{I}} \underbrace{-2 \gamma \frac{\partial x^{I}}{\partial a_{i}} z^{I}}_{\mathrm{II}} ; \\
(\mathrm{RDC}) s a_{i}^{R} & =\underbrace{z^{R}}_{\mathrm{I}} \underbrace{-2 \gamma \frac{\partial x^{R}}{\partial a_{i}} z_{i}^{R}}_{\mathrm{II}} \underbrace{-2 \gamma \frac{\partial z_{i}^{R}}{\partial a_{i}} x^{R}}_{\mathrm{III}} \underbrace{-\left(\frac{\partial z_{j}^{R}}{\partial a_{i}} z_{i}^{R}+\frac{\partial z_{i}^{R}}{\partial a_{i}} z_{j}^{R}\right)}_{\mathrm{IV}} .
\end{aligned}
$$

The marginal revenue of $\mathrm{R} \& \mathrm{D}$ can be decomposed into several parts in both options. Two parts are common to both options: part I is the direct positive effect stemming from the decrease in good $Z$ marginal cost of production; part II is an indirect positive effect stemming from the fact that the production of the old goods is negatively affected by an increase in R\&D efforts, which in turn induces an increase in the price of good $Z$ (up to $\gamma$ ). Two additional negative effects occur in option RDC: part III is an indirect negative effect stemming from the fact that the prices of the old goods decrease because of the increase in the production of good $Z$; part IV is another negative effect caused by the competition on the market for good $Z$. One understands thus that the Independent Joint Venture yields more intensive RED $D$ efforts than the RED Cartel. ${ }^{14}$ However, because production stages are

\footnotetext{
${ }^{14}$ As a matter of fact, it can be checked that option IJV yields the highest levels of specific assets among all six options.
} 
different, higher R\&D efforts in option IJV need not translate in higher equilibrium quantities of the new good; actually, for a given $\gamma, z^{I}>z^{R}$ provided that R\&D costs do not exceed some threshold (that increases with $\gamma$ ).

\subsubsection{Participation constraint}

Let us now turn to the second issue and examine which option the regulator should select taking into account the firms' participation constraint. To organize our thoughts, let us first recall some useful findings drawn from the previous analyses:

1. the participation constraint becomes stringent for the various options in a region of parameters where option IJV leads to the highest consumers surplus and social welfare;

2. one can show that in that region, option RDC is completely dominated by option CJV; ${ }^{15}$

3. option CJV yields higher consumers surplus and social welfare than option MER unless R\&D costs are very low;

4. profits are higher in the Cooperative than in the Independent Joint Venture over the whole range of parameters, meaning that the participation constraint is violated for a larger range of parameters under option IJV than under option CJV;

5. the Merger option always improves upon initial profits.

According to the last two findings, the area of $(\gamma, s)$ space where the participation constraint is violated under option IJV must be further divided into two zones: a first zone where option CJV meets the constraint and a second zone (corresponding to larger values of $\gamma$ for a given $s$ ) where it does not. Using the other three findings, it is clear that, in the second zone, the regulator can choose nothing but the Merger option, while, in the first zone, she can choose between options CJV and MER and we know that option CJV should be preferred unless $s$ is very close to its minimum admissible value.

\footnotetext{
${ }^{15}$ Sufficient conditions to have $W^{I}>W^{C}>W^{R}$ and $S^{I}>S^{C}>S^{R}$ are, respectively, $\gamma>.206$ and $\gamma>.273$; on the other hand, a necessary condition to have $\Pi^{L}<\Pi_{0}(L=$ $R, C, I)$ is $\gamma>.351$.
} 


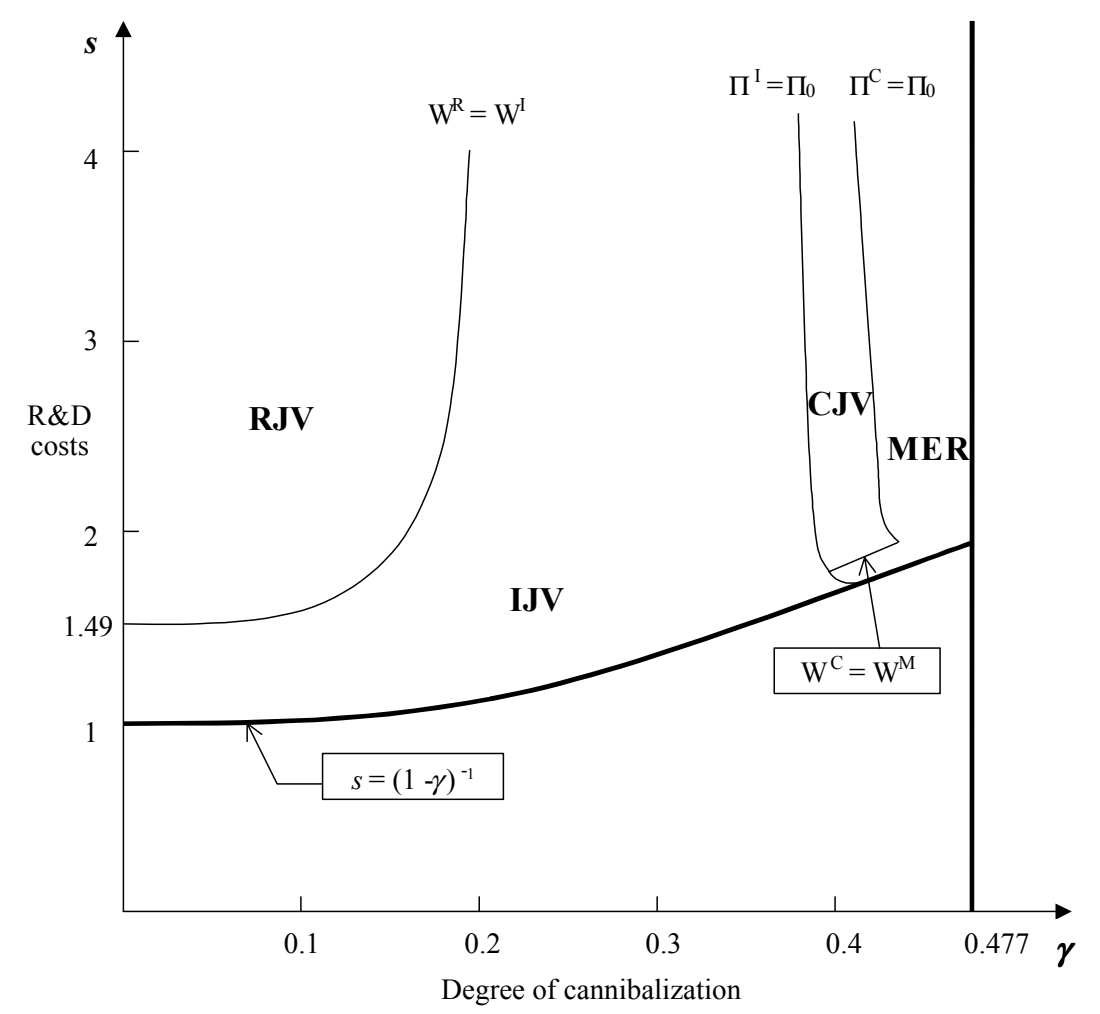

Figure 3: Solution to the constrained welfare maximization program

We are now in a position to identify, in the whole admissible range of parameters, which option leads to the highest welfare level while satisfying the firms' participation constraint. The solution is summarized in the following proposition and figure.

Proposition 4 The regulator's welfare maximizing choice between the six options under the firms' participation constraint depends on the values of the degree of cannibalization $(\gamma)$ and of the costs of RED $(s)$ as depicted in Figure 3.

\subsection{Social desirability of the new product}

The previous proposition indicates which of the six options the regulator should prefer under the constraint that she cannot force firms to enter into unprofitable agreements. In particular, it shows that when cannibalization is 
particularly strong, the complete merger is the only profitable agreement, and it should thus be preferred despite its low welfare performance. However, for the merger to be permitted, it still needs to pass a final test: it must improve social welfare on the level $W_{0}$ that would be achieved were the new product not introduced (and no R\&D carried out).

Using the results presented in Appendix A, simple computations establish that

$$
\begin{aligned}
W^{M} & =\frac{3\left(1-2 \gamma^{2}\right)(3-4 \gamma) s-2\left(7-4 \gamma-8 \gamma^{2}\right)+6}{8\left[\left(1-2 \gamma^{2}\right) s-1\right]^{2}}(\alpha-c)^{2}>\frac{3}{4}(\alpha-c)^{2}=W_{0} \\
& \Leftrightarrow s>\frac{2}{3\left(1-2 \gamma^{2}\right)},
\end{aligned}
$$

which is satisfied since, from condition $(\mathrm{C} 2), s>1 /(1-\gamma)$, and from condition (C1), $\gamma<.477$ implies that $1 /(1-\gamma)>2 /\left[3\left(1-2 \gamma^{2}\right)\right]$.

We have thus shown that the creation of the new good is socially desirable for the whole admissible range of parameters (meaning that even when the firms' participation constraint is violated, the increase in consumer surplus outweighs the profits lost by the firms). The following proposition records this result (which partly follows from the love for variety that the consumers' utility function exhibits).

Proposition 5 In a context where the creation of a new product involves RED investments by two parent firms whose existing products are substitute to the new one, complete merger between the parents should be permitted when cannibalization is strong and research costs are high: the introduction of the new product is indeed socially desirable, and the merger is the sole arrangement under which the firms will find it profitable to introduce it.

\section{Concluding remarks}

Over the last two decades, an abundant literature has investigated the private and social incentives for cooperation in Research and Development (R\&D) efforts between oligopolistic firms. The primary benefits and disadvantages of $R \& D$ cooperation have been shown to depend mainly on the degree of knowledge spillover between the firms and on the costs of $R \& D$ activities. For instance, it is established that when spillovers are sufficiently large, cooperation in $R \& D$ (with subsequent competition at the output stage) is welfareimproving. 
In this literature, the production stage concerns some isolated good market; that is, $\mathrm{R} \& \mathrm{D}$ activities allow to discover or to reduce the production costs of some new good which is assumed to be independent of any other good the participating firms could already be producing. In many situations, however, such assumption seems rather restrictive. For instance, the current process of "digital convergence"-i.e., the coming together of the telecommunications, information technology and audio-visual sectors-gives rise to new products that combine the characteristics of existing products and thereby appear as substitutes for these existing products. As a consequence, the introduction of such new products come at the expense of the sales of existing 'old' products, a phenomenon known as cannibalization. In such a context, R\&D activities directed towards the production of new goods have to be appreciated for their effects not only on the market for these goods, but also on the markets for old goods.

The aim of present paper was to re-assess the issue of cooperation in $R \& D$ by taking cannibalization into account. In a context where the firms can choose between a set of various options to collaborate in R\&D and/or in the production of a new product, we established the following results (assuming that spillovers are complete).

1. None of the options involving uncoordinated R\&D activities would ever be chosen either by the firms or by a regulator willing to maximize social welfare.

2. When cannibalization is not too strong, the welfare-maximizing collaborative agreement between parent firms is of the following form. In case of low R\&D costs, firms should form a separate entity that independently chooses the output level of the new good, and the level of R\&D expenditures. Otherwise, they should jointly decide about R\&D, but independently about production.

3. When cannibalization is strong, firms might find it unprofitable to market the new good unless they are allowed to narrowly collaborate with each other (on R\&D and on production). At the limit, a complete merger will be the only option under which the new good will appear. Merger should then be permitted by the regulator since it proves to enhance social welfare with respect to the situation where the new good is not introduced. 
The latter result is of particular interest for antitrust matters. It implies indeed that in the presence of strong cannibalization, mergers could be a necessary evil for the socially desirable introduction of new goods. The modeling framework used in this paper is, however, too specific to elaborate further on this issue.

Several extensions can be suggested to complement the present analysis.

- A first way to extend the present analysis would be to introduce uncertainty with respect to the size of the market for the new good. In our model, market size can be measured by the difference between $\alpha$ (intercept of the inverse demand curve) and $c$ (marginal cost of production). For the sake of simplicity we have assumed that this difference is the same for all goods before any process innovation. However, it would be more realistic to consider that market sizes for old and new products differ, and that firms are uncertain about the magnitude of this difference. Such uncertainty is likely to affect firms' incentives to internalize the cannibalization effect, and thereby to modify our results with respect to the choice of collaborative agreements.

- A second extension would be to allow for competition on the market for the new product. Such extension is of primary importance to analyse antitrust issues. In the present analysis, in order to focus on the cannibalization issue, we assumed that the parent firms were the only active firms on the market for the new product, and that there was no threat of entry. If this assumption is relaxed, R\&D efforts have also to be seen as a way of gaining market shares over incumbent firms or of preventing entry (because of the cost reduction impact of R\&D). Bresnahan and Salop (1986) and Reynolds and Snapp (1986) explore the competitive effects of production joint ventures, but leave aside R\&D.

- Finally, a third-and, in our view, more challenging-extension would consist in considering cooperation between asymmetric firms. We assumed here that the introduction of the new good affects the demand for the two existing goods in a symmetric way. It might however be the case that one of the parent firms suffers more from the creation of the new good than the other parent. ${ }^{16}$ A number of important questions

\footnotetext{
${ }^{16}$ For instance, the creation of "You've got Pictures!" is likely to do more harm to Kodak's core business than to AOL's.
} 
then arise with respect to the ownership and governance structures of the joint venture. Veugelers and Kesteloot (1996), Petit and Tolwinski (1999), and Belleflamme and Bloch (2000) consider joint ventures among asymmetric partners, but under different perspectives than the one envisioned here.

\section{References}

[1] Belleflamme, P., Bloch, F., 2000. Optimal ownership structures in asymmetric joint ventures. Mimeo, QMW College, University of London

[2] Bensaïd, B., Encaoua, D., Winckler, A., 1994. Competition, cooperation and mergers: Economic and policy issues. European Economic Review $38,637-650$.

[3] Bresnahan, T., Salop, S., 1986. Quantifying the competitive effects of production joint ventures. International Journal of Industrial Organization $4,155-175$.

[4] d'Aspremont, C., Jacquemin, A. 1988. Cooperative and noncooperative R\&D in duopoly with spillovers. American Economic Review 78, 11331137.

[5] d'Aspremont, C., Jacquemin, A. 1990. Cooperative and noncooperative R\&D in duopoly with spillovers: Erratum. American Economic Review 80, 641-642.

[6] De Bondt, R., Slaets, P., Cassiman, B., 1992. The degree of spillovers and the number of rivals for maximum effective R\&D. International Journal of Industrial Organization 10, 35-54.

[7] Kamien, M.I., Muller, E., Zang, I., 1992. Research joint ventures and R\&D cartels. American Economic Review 82, 1293-1306.

[8] Katz, M., Ordover, J.A., 1990. R\&D cooperation and competition. Brookings Papers on Economic Activity 6, 137-191.

[9] Leahy, D., Neary, P. 1997. Public policy towards R\&D in oligopolistic industries. American Economic Review 87, 642-662. 
[10] Petit, M.L., Tolwinski, B., 1999. R\&D cooperation or competition? European Economic Review 43, 185-208.

[11] Reynolds, R., Snapp, B., 1986. The competitive effects of partial equity interests and joint ventures. International Journal of Industrial Organization 4, 141-153.

[12] Veugelers, R., Kesteloot, K., 1996. Bargained shares in joint ventures among asymmetric partners: Is the Matthew effect catalyzing? Journal of Economics (Zeitschrift für Nationalökonomie) 64, 23-51.

[13] Suzumura, K., 1992. Cooperative and noncooperative R\&D in oligopoly with spillovers. American Economic Review 82, 1307-1320.

\section{Appendices}

\subsection{Equilibrium of the six two-stage games}

Table 2 presents the perfect equilibrium levels of industry assets and of output for the three goods in the six options. ${ }^{17}$

Using the first-order conditions for profit maximization at the production stage, one can easily express industry profits corresponding to the various options as follows (where variables are evaluated at their perfect equilibrium level).

- Options TSC and RDC:

$$
\Pi^{K}=x^{2}+y^{2}+z_{1}^{2}+z_{2}^{2}+2 \gamma\left(x z_{1}+y z_{2}\right)-\frac{s}{2}\left(a_{1}^{2}+a_{2}^{2}\right)(K=T, R) .
$$

- Options PJV, CJV and IJV:

$$
\Pi^{L}=x^{2}+y^{2}+z^{2}-\frac{s}{2}\left(a_{1}^{2}+a_{2}^{2}\right)(L=P, C, I) .
$$

\footnotetext{
${ }^{17}$ Note that $\beta=\alpha-c$ should appear as a multiplying factor in every cell of Table 2 ; to simplify the exposition, we arbitrarily set $\beta$ to unity; this assumption does not harm the welfare analysis since it only deals with comparisons between the different options (where the common factor $\beta$ inevitably cancels out). Note also that because of the symmetry of the models, the equilibrium levels of $X$ and $Y$ are equal.
} 
Table 2: Synthesis of perfect equilibrium asset and ouput levels

\begin{tabular}{cccc}
\hline & $a_{1}+a_{2}$ & $x=y$ & $z$ or $z_{1}+z_{2}$ \\
TSC & $\frac{4\left[\left(4-3 \gamma^{2}\right)-9 \gamma\left(1-\gamma^{2}\right)\right]}{9\left(2-3 \gamma^{2}\right)^{2} s-4\left(4-3 \gamma^{2}\right)}$ & $\frac{\left(2-3 \gamma^{2}\right)[9(1-\gamma) s-4]}{9\left(2-3 \gamma^{2}\right)^{2} s-4\left(4-3 \gamma^{2}\right)}$ & $\frac{2\left[3(2-3 \gamma)\left(2-3 \gamma^{2}\right) s-4 \gamma\right]}{9\left(2-3 \gamma^{2}\right)^{2} s-4\left(4-3 \gamma^{2}\right)}$ \\
$R D C$ & $\frac{8\left[\left(4-3 \gamma^{2}\right)-9 \gamma\left(1-\gamma^{2}\right)\right]}{9\left(2-3 \gamma^{2}\right)^{2} s-8\left(4-3 \gamma^{2}\right)}$ & $\frac{\left(2-3 \gamma^{2}\right)[9(1-\gamma) s-8]}{9\left(2-3 \gamma^{2}\right)^{2} s-8\left(4-3 \gamma^{2}\right)}$ & $\frac{2\left[3(2-3 \gamma)\left(2-3 \gamma^{2}\right) s-8 \gamma\right]}{9\left(2-3 \gamma^{2}\right)^{2} s-8\left(4-3 \gamma^{2}\right)}$ \\
$P J V$ & $\frac{2-4 \gamma+\gamma^{2}}{\left(2-\gamma^{2}\right)^{2} s-\left(2+\gamma^{2}\right)}$ & $\frac{(2-\gamma)\left(2-\gamma^{2}\right) s-2}{2\left[\left(2-\gamma^{2}\right)^{2} s-\left(2+\gamma^{2}\right)\right]}$ & $\frac{(1-\gamma)\left(2-\gamma^{2}\right) s-\gamma}{\left(2-\gamma^{2}\right)^{2} s-\left(2+\gamma^{2}\right)}$ \\
CJV & $\frac{2\left(2-4 \gamma+\gamma^{2}\right)}{\left(2-\gamma^{2}\right)^{2} s-2\left(2+\gamma^{2}\right)}$ & $\frac{(2-\gamma)\left(2-\gamma^{2}\right) s-4}{2\left[\left(2-\gamma^{2}\right)^{2} s-2\left(2+\gamma^{2}\right)\right]}$ & $\frac{(1-\gamma)\left(2-\gamma^{2}\right) s-2 \gamma}{\left(2-\gamma^{2}\right)^{2} s-2\left(2+\gamma^{2}\right)}$ \\
IJV & $\frac{4(1-\gamma)}{\left(2-\gamma^{2}\right)^{2} s-4}$ & $\frac{(2-\gamma)\left(2-\gamma^{2}\right) s-4}{2\left[\left(2-\gamma^{2}\right)^{2} s-4\right]}$ & $\frac{(1-\gamma)\left(2-\gamma^{2}\right) s}{\left(2-\gamma^{2}\right)^{2} s-4}$ \\
MER & $\frac{(1-2 \gamma)}{\left(1-2 \gamma^{2}\right) s-1}$ & $\frac{(1-\gamma) s-1}{2\left[\left(1-2 \gamma^{2}\right) s-1\right]}$ & $\frac{(1-2 \gamma) s}{2\left[\left(1-2 \gamma^{2}\right) s-1\right]}$ \\
\hline
\end{tabular}

- Option MER:

$$
\Pi^{M}=x^{2}+y^{2}+z^{2}+2 \gamma(x+y) z_{M}-\frac{s}{2}\left(a_{1}^{2}+a_{2}^{2}\right) .
$$

As far as the consumers surplus is concerned, it is readily computed by combining expressions (1) and (2), yielding the same formulation for all options:

$$
\begin{aligned}
S^{K} & =U(x, y, z)-p x-q y-r z \\
& =\frac{1}{2}\left(x^{2}+y^{2}+z^{2}\right)+\gamma(x+y) z(K=T, R, P, C, I, M) .
\end{aligned}
$$

Finally, social welfare is defined as the sum of industry profits and consumers surplus:

$$
W^{K}=\Pi^{K}+S^{K}(K=T, R, P, C, I, M) .
$$

\subsection{Participation constraint}

Regarding the firms' participation constraint, simple computations show that in all options but the Merger option, one can find, for sufficiently high values 
of $\gamma$, values of $s$ for which the participation constraint is violated.We state here the relevant conditions for options RDC, CJV and IJV. That is, in options RDC, CJV and IJV, industry profits are lower than initial profits if the following conditions hold:

$$
\begin{aligned}
& \text { - option RDC, } \gamma>0.351 \text { and } s>\frac{8 \gamma^{2}}{(2-3 \gamma)\left(-8+24 \gamma+6 \gamma^{2}-27 \gamma^{3}\right)} \\
& \text { - option CJV, } \gamma>0.363 \text { and } s>\frac{2 \gamma^{2}}{-2+8 \gamma-7 \gamma^{2}+\gamma^{4}} \\
& \text { - option IJV, } \gamma>0.363 \text { and } s>\frac{8\left(1-3 \gamma+\gamma^{3}\right)}{\left(2-3 \gamma^{2}\right)^{2}\left(2-6 \gamma+\gamma^{2}+\gamma^{3}\right)}
\end{aligned}
$$

